\title{
l. Dossier: Nuevas aproximaciones a la historia económica regional. Crecimiento económico, riqueza y distribución de factores productivos en la Argentina del siglo XIX
}

Julio Djenderedjian ${ }^{1}$

\section{Presentación del dossier}

L os tres trabajos que aquí presentamos, realizados por jóvenes investigadores, _ constituyen miradas novedosas y creativas sobre el panorama de la historia económica argentina del siglo XIX. A través de un trabajo minucioso, lograron resolver algunos problemas típicos que suelen presentarse a los estudiosos que (lidiando con fuentes de etapas preestadísticas, es decir, insalvablemente pobres) intentan comprender la dinámica y la complejidad de la distribución de la propiedad de los factores mediante un estudio profundo de espacios regionales acotados, en momentos en que los mercados de esos factores poseían, justamente, un carácter puramente local. No es casualidad tampoco que el análisis se centre en momentos de peculiar dinamismo económico, que incluyen claro está coyunturas de crecimiento y de atonía, y que por eso mismo exigen gran atención a los detalles y suficiente sensibilidad para identificar las causas que están detrás de los frecuentes cambios de situación. Las formas que adoptaron la generación y distribución de la riqueza constituyen, por tanto, un horizonte de preguntas presente en todos, si bien con muy diferentes matices y énfasis. Luego de efectuar un inventario nominal de esa riqueza, necesario no tanto por imposición de la agenda de investigación en sí sino sobre todo por la exigencia de construir previamente, con elementos ciertos, un perfil adecuado del área bajo estudio, en esencia lo que se trató de responder es cómo evolucionó esa riqueza hasta el punto en que ha sido inventariada. Esto es: cómo fue creada, cómo circulaba, cuál era su valor relativo y cómo se explican los a menudo fuertes cambios que se presentan al saltar de un año a otro o de uno a otro

1 Instituto de Historia Argentina y Americana "Dr. Emilio Ravignani” Universidad de Buenos Aires/Consejo Nacional de Investigaciones Científicas y Técnicas. Correo electrónico: juliodjend@ yahoo.com.ar 
sitio aun dentro de una misma localidad. Para ello, todos apuntan asimismo a evaluar los límites y las posibilidades del contexto en que esos fenómenos tuvieron lugar, brindando así un panorama más conciso hasta ahora disponible. De allí a analizar los peculiares grados de concentración y dispersión de esa riqueza entre sus diferentes tenedores, y qué diferencias pueden establecerse al compararlas con las mediciones existentes fuera del espacio puntual estudiado, sólo hay un corto trecho que puede o no haber sido recorrido aquí, pero que de cualquier modo está también presente. Porque las preguntas que subtienden todos los trabajos implican de una manera u otra el diálogo tácito o explícito con quienes han debido lidiar con problemas prácticos también muy similares, aquí o en cualquier otra parte. Lo cual otorga una dimensión particular a estos estudios de caso: en modo alguno empiezan y terminan en sí mismos.

Más allá de si el análisis ha sido o no efectuado en torno a un momento puntual (hecho debido a menudo a la disponibilidad o características de las fuentes) subyace por lo demás en todos una visión diacrónica, que es el secreto motor de su eficacia. Aun cuando no siempre haya sido explicitado, el objetivo último es entender los cambios, partiendo eso sí de una base de medición lo suficientemente sólida como para que ese punto de inicio pueda constituirse en ordenador de la investigación. Lo cual resulta particularmente útil dada la peculiar falta de registros seriados que aqueja al espacio rioplatense durante las seis o siete primeras décadas del siglo XIX, vacío que recién desde hace relativamente poco tiempo, y gracias a un gran trabajo empírico, se ha comenzado a salvar. En el contexto de una economía signada por súbitas y significativas mutaciones, la pregunta en torno a qué puede saberse sobre las múltiples variaciones de fortuna ligadas al ciclo de vida personal apunta así a elaborar una explicación que cierre de alguna manera la brecha entre los vastos testimonios impresionistas autorizados hasta ahora por la falta de mediciones, y las historias concretas que si bien adolecen de realidad no permiten avanzar más allá de ella. La búsqueda de una explicación, no presente por lo general cuando el énfasis apenas abarca el objeto bajo análisis, está por el contrario aquí en el centro del esquema: las preguntas y los objetivos exceden largamente los casos puntuales, y en ello pueden entreverse los efectos del sustancial avance logrado por la historia económica argentina en los últimos años. No hace falta destacar que se trata de estudios realizados con un inédito nivel de detalle; no únicamente en ello están acordes con el grado de sofisticación alcanzado por la especialidad. Más importante aún es que en todos los casos esos ejemplos han sido mirados desde ángulos originales, definidos a partir del conocimiento de una vasta bibliografía relativa y de los aportes efectuados por un largo censo de estudiosos tanto en el país como en el extranjero. Lo cual llevó a considerar 
los problemas planteados desde una dimensión nueva. La misma podrá o no impugnar multitud de ideas aceptadas, que no tenían sufriente solidez por no haber tenido tampoco base empírica; más allá de ello, tanto el recorte regional como la prueba pacientemente recogida y exhaustivamente analizada, implican por sí mismos un cambio de magnitud en la forma de resolver aquellos problemas. Es decir: lo original no se encuentra ya en el hecho de desvelar la incógnita que constituían esos espacios en tanto microcosmos, sino en la forma en que esa dimensión acotada y regional ha sido constituida en una vía útil para poder analizar integralmente problemas planteados en lugar privilegiado por la agenda internacional de los especialistas, pero cuya solución sólo podía ser encarada satisfactoriamente desde esa dimensión local. Concentrarse en el área que circunda al pueblo de Mercedes constituye para Fernanda Barcos un útil pretexto para mostrarnos la complejidad de los ejidos como espacios productivos y de acumulación, pero también, y sobre todo, las formas y los ritmos de la movilidad de los patrimonios personales a lo largo de un período de más de una década, por otra parte enormemente agitada; el estudio de la ciudad de Buenos Aires por Tomás Guzmán nos exhibe las particularidades de la generación y concentración de riquezas en una urbe de dimensiones realmente considerables, y por tanto no contaminada por la perenne influencia de una campaña demasiado cercana, pero de la cual es a la vez cabeza y principal prestadora de servicios, quedándose por tanto con una parte considerable de la renta creada por aquélla; y el estudio sobre San Carlos y Esperanza de Juan Martirén nos muestra cómo dos sorprendentes fenómenos (el proceso de colonización y el surgimiento de un mercado inmobiliario), cuya íntima conexión siempre ha sido presupuesta, no necesariamente han sostenido una relación ni mecánica ni unívoca, aun en dos casos supuestamente construidos a partir de un impulso común y cuyas coordenadas básicas de utilización de factores debían también, supuestamente, ser similares.

La captación de los rasgos esenciales de esos mercados de factores y, con mayor razón aún, la descripción y análisis de las formas en que unos y otros actores concretos fueron finalmente agraciados con porciones más o menos considerables de la creación de valor, se vieron dificultadas por múltiples problemas: aparte de la ya mencionada falta o escasez de fuentes seriadas, incompatibilidad de recuentos efectuados en distintos momentos pero también con distintos criterios; largos conjuntos de datos cuya compilación y tratamiento implicaba un duro esfuerzo; necesidad de construir métodos aptos para resolver los sesgos de las muestras, siempre dispuestos a torcer los resultados por sus propias limitaciones. Todo ello ha sido atendido y zanjado con solvencia. Si quizá en algún aspecto los métodos empleados o desarrollados puedan ser aún 
materia de controversia, lo concreto es que se ofrecen en estos trabajos algunas respuestas concretas y razonables, y por tanto vías de solución admisibles a puntos que hasta hoy siguen constituyendo claves fundamentales del devenir económico del siglo XIX.

Lo cual no quita por supuesto valor a lo que estos aportes resuelven a nivel regional, o a lo que respecta al tratamiento del tema si lo miramos desde dimensiones menos amplias. Por fortuna contamos ya con excelentes investigaciones en torno al mercado inmobiliario rural en Buenos Aires; pero poco o nada sabíamos sobre los espacios productivos más cercanos a los pueblos, cuya complejidad constituía no sólo una incógnita sino una rémora en tanto no éramos capaces de percibir hasta qué punto su importancia económica afectaba al conjunto. Seguir dentro de él las fortunas individuales en su evolución durante un período agitado y aun a pesar de múltiples inconvenientes brinda así una base útil para otorgar cuerpo concreto a un sector de marcada importancia económica; y para poder contar con una imagen menos impresionista de las posibilidades que brindaba aquella economía más allá de sus sectores más dinámicos. Si bien el proceso de colonización santafesino ha sido estudiado repetidas veces, no contábamos hasta hoy con una explicación de las lógicas de funcionamiento del mercado inmobiliario que fue su consecuencia, aparte de hipótesis sin duda razonables; el hecho de contar con un examen detallado y completo de las transacciones inmobiliarias nos muestra los pormenores recónditos donde se encontraban las claves de esa evolución, que podían ser muy distintas según hubiera sido concebido el punto de partida. Combinar ello con la identificación y seguimiento de los cambios en la posición en la escala de riqueza de cada individuo a lo largo del tiempo conformó un diagrama esencial para comprender cómo esa planificación inicial, y más alla de las decisiones personales tomadas por los actores, tuvieron parte considerable en el recorrido y resultados obtenidos por éstos. Por fin, la distribución de la riqueza en los espacios rurales ha sido analizada a partir de diversas fuentes y para distintos momentos; pero estaba aún pendiente de respuesta la incógnita acerca del carácter de la misma en la gran ciudad de Buenos Aires, cuya lógica podía ser completamente diferente de aquéllos, y es un hecho que guarda sustanciales diferencias que no pueden ser atribuidas a las propias características del medio. Pero de todos modos no se trataba sólo de completar los faltantes en una interesante colección de casos: más importante aún era plantear interrogantes anteriormente no tratados y haber obtenido para ellos respuestas que abren aún más el panorama de secretos a develar. Y sin duda quien los busque hallará aquí abundante material para formular preguntas que vayan mucho más allá del campo ya de por sí amplio de la historia económica. 
Por todo ello, considero que los trabajos aquí reunidos constituyen un aporte sustancial al conocimiento de la historia económica argentina en el siglo XIX, y no me caben dudas de que serán muy útiles, más allá del ámbito de los investigadores con curiosidades similares. 